\title{
Placental Up-Regulation of Leptin and ARMS2 is Associated with Growth Discordance in Monochorionic Diamniotic Twin Pregnancies
}

\author{
Luming Sun, ${ }^{1,2,3}$ Jia Zhou, ${ }^{1}$ Kai Wang, ${ }^{1}$ Jian Wang, ${ }^{2,3}$ Ling Shang, ${ }^{4}$ Jianguang Zhang, ${ }^{4}$ Junqing Wu, ${ }^{2,3}$ \\ and David S. Cram ${ }^{4,5}$ \\ ${ }^{1}$ Fetal Medicine Unit and Prenatal Diagnosis Center, Department of Obstetrics, Shanghai First Maternity and Infant \\ Hospital, Tongji University School of Medicine, Shanghai, China \\ ${ }^{2}$ School of Public Health of Fudan University, Shanghai, China \\ ${ }^{3}$ Shanghai Institute of Planned Parenthood Research/WHO Collaborating Center on Human Reproduction, Shanghai, China \\ ${ }^{4}$ Berry Genomics Corporation, Chaoyang District, Beijing, China \\ ${ }^{5}$ Department of Anatomy and Developmental Biology, Monash University, Melbourne, Victoria, Australia
}

\begin{abstract}
Fetal growth discordance is a relatively common complication of monochorionic diamniotic (MCDA) twin pregnancies and is caused by a combination of maternal and placental factors. The aim of the study was to survey placental gene expression patterns and identify genes associated with growth discordance. Clinical samples comprised eight growth-discordant MCDA twin placentas $\left(31^{+3}-34^{+4}\right.$ weeks gestational age $)$ and six growth-concordant twin placentas $\left(31^{+2}-37\right.$ weeks gestational age). Gene expression libraries were constructed from placental biopsy samples and analyzed by RNA-sequencing. The distribution and relative abundance of mRNA transcripts expressed in the smaller and larger placentas from growth-discordant and concordant MCDA twins was remarkably similar. However, leptin (LEP) and age-related maculopathy susceptibility 2 (ARMS2) mRNA levels were exclusively up-regulated in all of the eight smaller growthdiscordant twin placentas. Quantitative real-time PCR of independent biopsy samples confirmed the levels of differential mRNA expression for both genes. Immunohistochemical analysis of tissue sections from matching twin placentas showed increased leptin expression in $5-10 \%$ of blood vessel cells of the smaller placenta and marginally higher levels of ARMS2 expression in the microvillous membrane of the smaller placenta. Based on these findings, we speculate that up-regulation of leptin and ARMS2 forms part of an important survival mechanism to compensate for placental growth discordance. Since, leptin and ARMS2 are both expressed as soluble proteins, they may have clinical potential as measurable biomarkers for predicting the onset of growth discordance in MCDA twin pregnancies.
\end{abstract}

Keywords: monochorionic diamniotic, placenta, growth discordance, RNA sequencing, leptin, ARMS2

Fetal growth restriction (FGR) is a failure to fulfill the genetically predetermined growth potential during the course of pregnancy. The causes of FGR can be broadly subdivided into fetal, maternal, and placental etiologies. Identification of the contributing environmental and genetic factors, combined with an understanding of the pathological changes preceding development of FGR, is essential so that future care can be targeted toward developing potential therapies to alleviate adverse perinatal outcomes. Based on a plethora of studies, placental insufficiency has been consistently shown to be involved in the majority of FGR cases (Simonazzi et al., 2013). However, in previous studies (Cosmi et al., 2013; McCarthy et al., 2007; Sitras et al., 2009) where a singleton fetus was used as a model to study the role of placental inefficiency in the pathogenesis of FGR, contributions of maternal, genetic, and metabolic factors were still evident.

RECEIVED 13 September 2016; ACCEPTED 25 January 2017

ADDRESS FOR CORRESPONDENCE: David S. Cram, Berry Genomics Corporation, Building 9, No 6 Court Jingshun East Road, Chaoyang District, Beijing, 100015, China. E-mail: david. cram@berrygenomics.com; Luming Sun, Shanghai First Maternity and Infant Hospital, Tongji University School of Medicine, No. 2699, Gaoke West Road, Pudong New Area, Shanghai, 201204, China. E-mail: luming_sun@163.com 
TABLE 1

Clinical Characteristics of MCDA Pregnancies and Twin Placentas

\begin{tabular}{|c|c|c|c|}
\hline \multirow[b]{2}{*}{ Clinical data } & \multicolumn{2}{|c|}{ RNA and qPCR studies } & \multirow{2}{*}{$\begin{array}{c}\text { qPCR studies } \\
\text { Growth-concordant MCDA } \\
\text { twin placentas }(n=3)\end{array}$} \\
\hline & $\begin{array}{l}\text { Growth-discordant MCDA } \\
\text { twin placentas }(n=8)\end{array}$ & $\begin{array}{l}\text { Growth-concordant MCDA } \\
\text { twin placentas }(n=3)\end{array}$ & \\
\hline Maternal age (years) & $28.3 \pm 3.62$ & $28.0 \pm 5.0$ & $30.0 \pm 3.5$ \\
\hline $\begin{array}{l}\text { Estimated fetal weight }<10 \text { th percentile } \\
\text { for smaller fetus }(n)\end{array}$ & 8 & 0 & 0 \\
\hline $\begin{array}{l}\text { Absent/reverse end diastolic flow in } \\
\text { umbilical artery doppler ( } n)\end{array}$ & 8 & 0 & 0 \\
\hline Birth weight $(g)$ & $1747.6 \pm 370.4$ & $2712.2 \pm 169.5$ & $1869.2 \pm 338.6$ \\
\hline Large $(g)$ & $2030.1 \pm 204.3$ & $2813.3 \pm 132.0$ & $1930.0 \pm 404.5$ \\
\hline Small (g) & $1465 \pm 264.1$ & $2611.0 \pm 153.9$ & $1808.3 \pm 334.5$ \\
\hline Birth weight discordance (\%) & $28.2 \pm 6.9$ & $7.1 \pm 5.0$ & $5.9 \pm 2.8$ \\
\hline Male/female & $10 / 6$ & $6 / 0$ & $2 / 4$ \\
\hline Placental weight $(\mathrm{g})$ & $756.3 \pm 127.4$ & $920.0 \pm 70.7$ & $683.3 \pm 112.4$ \\
\hline Average gestational age (weeks) & $33.4 \pm 1.21$ & $36.8 \pm 0.3$ & $33.0 \pm 1.5$ \\
\hline Gestational age weeks (range) & $31^{+3}-34^{+4}$ & $36^{+3}-37$ & $31^{+2}-34^{+1}$ \\
\hline
\end{tabular}

Growth discordance is one of the most common complications of monochorionic diamniotic (MCDA) twin pregnancies (Bejar et al., 1990; Valsky, Eixarch, Martinez, Crispi et al., 2010), with a prevalence of $10-19 \%$ (Acosta-Rojas et al., 2007; Lewi et al., 2014; Valsky, Eixarch, Martinez, \& Gratacós, 2010). The mechanisms and progressive development of growth discordance largely depend on the relative effects of unequal placental sharing and inter-twin blood transfer through placental anastomoses (Chang et al., 2009; Hack et al., 2008; Lewi et al., 2007). MCDA twins share the same genetic background and maternal host environment. Thus, the differences in intrauterine growth of MCDA twins may be due to differential regulation of genes at the transcriptional and/or post-transcriptional level that are involved in placental development and function. On this basis, growth-discordant MCDA twins represent ideal models to study the underlying mechanisms of placental insufficiency independent of confounding genetic factors and maternal host environment.

Previous twin studies have demonstrated that phenotypic placental variation is associated with epigenetic factors (Bell \& Saffery, 2012; Gordon et al., 2011; Kaminsky et al., 2009; Yu et al., 2012). In a recent study, that specifically examined placental mRNA expression of angiogenesisrelated genes, significant up-regulation in the placental share of the growth-discordant MCDA twin for leptin $(L E P)$ and several other angiogenic factors were reported (Schrey et al., 2013). In other studies, differential expression of osteopontin (Li et al., 2013) and the human endogenous family W, $\operatorname{Env}(\mathrm{C} 7)$, member 1 protein (Gao et al., 2012) were both found to be strongly associated with growth discordance. While there have been several studies focused on global gene expression in growth-discordant MCDA twin placentas (Gordon et al., 2011; Nishizawa et al., 2011; Sitras et al., 2009), cross-study analysis of the differentially expressed genes identified found no consensus genes strongly associated with growth discordance (Marr et al., 2016).
In order to shed further light on the key placental genes associated with growth discordance, our study compared the placental mRNA expression profiles between eight sets of growth-discordant MCDA twins using RNA sequencing (RNA-seq), which is now a well-established methodology to detect and quantitate the levels of genome-wide expressed transcripts in two closely related samples (Mortazavi et al., 2008). Thus, the identification of any differentially expressed placental genes between growth-discordant MCDA twin placentas would, therefore, be a proxy measure of epigenetic discordance. In this study, we identified two placental proteins, namely $L E P$ and age-related maculopathy susceptibility 2 (ARMS2), which were strongly associated with growth discordance in MCDA twins.

\section{Material and Methods}

\section{Ethics Statement}

The research study was approved by the Human Research Ethics Committee of the Shanghai First Maternity and Infant Hospital (KS1677, June 2016-June 2019). Prior to delivery, patients provided written informed consent for the research studies conducted on their placental tissue collected after delivery.

\section{Clinical Characteristics of Placental Samples}

The selected study samples (Table 1) consisted of eight growth-discordant MCDA twin placentas and six growthconcordant MCDA twin placentas without complications (Table 1). MCDA twins were selected by chorionicity confirmation from ultrasound during the first trimester and placental pathology after birth. Growth-discordant MCDA twins selected for the study were defined by more than a $20 \%$ birth-weight discordance, according to the formulae $(A-B) \times 100 / A$, where $A$ is the birth weight of the larger twin, and $B$ is the birth weight of the smaller twin (Lewi et al., 2014). Conversely, growth-concordant MCDA twins were defined as having a birth-weight discordance 
less than 10\% (Lewi et al., 2014) and normal umbilical artery doppler for both fetuses (Gratacós et al., 2007; Valsky, Eixarch, Martinez, Crispi et al., 2010). Other MCDA complications, such as preeclampsia, twin-to-twin transfusion, twin anemia-polycythemia sequence, fetal structural abnormalities, genetic syndromes, or chromosomal abnormalities were excluded. All pregnant women recruited to the study had no maternal or pregnancy complications.

\section{Collection of Placental Tissue and Isolation of RNA}

Immediately following delivery, pieces of tissue (approximately $100 \mathrm{mg}$ ) were removed from the middle portion of the placenta, which was identified by inter-twin membrane, each cord insertion, and placental vessel distributions. The biopsied tissue was washed repeatedly in phosphatebuffered saline to remove all traces of contaminating blood, snap frozen in liquid nitrogen, and then stored at -80 degree Celsius. Frozen tissue $(\sim 100 \mathrm{mg}$ sliced into smaller fragments) was placed directly into $1.5 \mathrm{ml}$ siliconized eppendorf tubes containing $1 \mathrm{ml}$ of Trizol solution (Qiagen). Total RNA was extracted according to the recommended protocol. In brief, tissue was homogenized and then tubes incubated at room temperature for at least $5 \mathrm{~min}$ to dissociate nucleoprotein complexes. Following addition of $0.2 \mathrm{ml}$ of chloroform and vigorous vortexing for $15 \mathrm{~s}$, tubes were further incubated at room temperature for $3 \mathrm{~min}$. Tubes were centrifuged at $12,000 \mathrm{xg}$ for $15 \mathrm{~min}$ at 4 degree Celsius and the aqueous phase transferred to a fresh tube. Glycogen $(10 \mu \mathrm{g})$ was added and RNA precipitated by addition of $1 \mathrm{ml}$ absolute ethyl alcohol and incubation at $-80 \mathrm{de}$ gree Celsius for 1 hour. Tubes were centrifuged at 12,000xg for $10 \mathrm{~min}$ at 4 degree Celsius, the RNA pellet washed with $75 \%$ ethanol, briefly air-dried, and then finally dissolved in RNase-free water. The concentration $(260 \mathrm{~nm}$ absorbance) and quality of the purified RNA (260 nm/280 nm absorbance ratio) was determined by Nanodrop-c (Thermo Scientific).

\section{RNA Sequencing and Data Analysis}

Poly $\mathrm{A}^{+}$containing mRNA was isolated from total RNA using poly-T oligo-attached magnetic beads (Illumina, US). A total of $100 \mathrm{ng}$ of poly $\mathrm{A}^{+}$mRNA was fragmented into an average size of $300 \mathrm{bp}$ by incubation in $100 \mathrm{mM} \mathrm{MgCl}_{2}$ at 95 degree Celsius for 3 min. Fragmented mRNA was reverse transcribed into first strand cDNA using random primers and reverse transcriptase, then copied to double stranded DNA using DNA polymerase and RNase H (Enzymatics, US). Following fragment end repair using DNA modifying enzymes T4 DNA polymerase, Klenow and T4 polynucleotide kinase and, addition of a single A base to the $5^{\prime}$ ends using Klenow Fragment ( $3^{\prime}$ to $5^{\prime}$ exo-), sequencing adaptors (Liang et al., 2013) were ligated to each end and then fragments finally amplified by PCR to generate the placental cDNA libraries. Libraries were then subjected to massively parallel sequencing on the Illumina HiSeq2500 platform to produce in the order of 20 million $2 \times 100 \mathrm{bp}$ paired end reads.

Paired end reads were uniquely mapped to the hg19 reference genome and contiguous sequences aligned using the TopHat2 algorithm (Kim et al., 2013) incorporated in the web-based analysis protocol http://ccb.jhu.edu/software/ tophat/index.shtml. The relative abundance of each transcript was normalized by calculating the reads per kilobase per one million reads (RPKM values; Mortazavi et al., 2008) according to the formula RPKM = total exon reads/mapped reads (millions) $\times$ exon length $(\mathrm{kb})$. The significance $(p$ value) of the level of individual gene expression was calculated from the ratio of the RPKM values determined for the small and large placental samples, using the edgeR algorithm (Robinson et al., 2010). In a Microsoft excel sheet, significant transcripts $(p$ value $<.05)$ showing $>2$-fold change in gene expression between the eight small and large growth-discordant twin placental samples (columns) were ordered by gene name (rows), allowing identification of differentially expressed genes.

\section{Quantitative Real-Time PCR}

Quantitative real-time PCR (qPCR) to quantitate relative gene expression levels between placental RNA samples was performed using the Kapa SYBR qPCR kit (KAPABIOSYSTEMS) according to the recommended protocol. Briefly, 20 $\mu l$ reactions were prepared in $200 \mu \mathrm{l}$ PCR tubes comprising $10 \mu l$ of Kapa SYBR FAST qPCR master mix ABI Prism, $0.4 \mu \mathrm{l}$ of $10 \mu \mathrm{M}$ forward primer, $0.4 \mu \mathrm{l}$ of $10 \mu \mathrm{M}$ reverse primer, $2 \mu \mathrm{l}$ of cDNA (20 ng) and $7.2 \mu \mathrm{l}$ of molecular grade water. Reactions were heated at 95 degree Celsius for $3 \mathrm{~min}$ to activate the heat stable DNA polymerase and then subjected to 40 two-step PCR cycles of 95 degree Celsius for 3 $\mathrm{s}$ and 60 degree Celsius for $25 \mathrm{~s}$. Melting curve analysis was performed and fold changes between comparative samples calculated by the delta delta $\mathrm{C}_{\mathrm{T}}$ method, with data normalized using the expression levels of the house keeping gene $\beta$-actin.

\section{Immunohistochemical Analysis}

Paraffin-embedded placental tissue biopsies were cut into $5 \mu \mathrm{m}$ sections, deparaffinized with xylene, and then gradually rehydrated with decreasing concentrations of ethyl alcohol. Boiled $10 \mathrm{mM}$ citrate buffer ( $\mathrm{pH}$ 6.0) was used for antigen retrieval and endogenous peroxidase activity was blocked in 3\% hydrogen peroxidase prepared in PBS. After blocking further with $10 \%$ rabbit serum, sections were probed overnight at 4 degree Celsius with either rabbit anti-LEPTIN antibody (1:100, Proteintech, USA) or rabbit anti-ARMS2 antibody (1:200, Novus, USA). Specific protein expression was visualized using the EnVision Peroxidase/DAB detection system (Dako, Denmark) according to the manufacturer's instructions. Negative control sections were treated similarly, except the primary antibody, was excluded. 


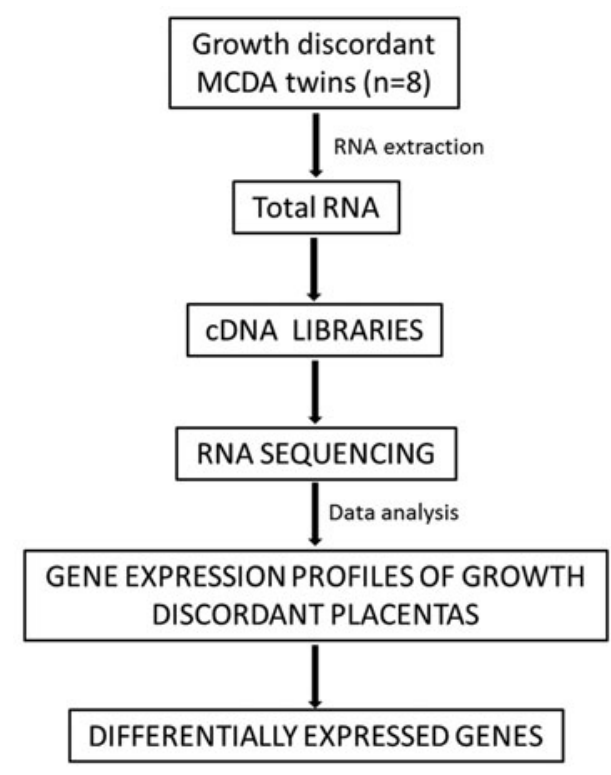

FIGURE 1.

Study design to identify placental genes associated with growth discordance.

\section{Results}

The overall study design to identify differentially expressed genes associated with growth-discordant twins is shown in Figure 1. We initially, compared gene expression patterns by RNA-seq between the larger and smaller placentas of eight growth-discordant MCDA twins (144, 149, 152, 166, 170, 197,202 , and 228) with an average gestational age of $33.4 \pm$ 1.21 weeks, range $31^{+3}-34^{+4}$ weeks (Table 1 ). As controls, we also analyzed the gene expression patterns in the smaller and larger placentas of three MCDA growth-concordant twins $(234,262$, and 272) with a slightly higher average gestational age of $36.8 \pm 0.3$ weeks, range $36^{+3} \pm 37$ weeks. We hypothesized that by comparing these two sets of clinically well-defined placental samples, any genes associated with growth discordance would be differentially expressed in smaller of the two growth-discordant placentas but not differentially expressed in the smaller of the two growthconcordant placentas.

Poly $\mathrm{A}^{+}$cDNA libraries were generated from growthdiscordant and concordant placental pairs and subjected to deep sequencing. By Pearson correlation, the transcript profiles between the smaller and larger placenta pairs were highly concordant (range $R^{2}$ values of $0.832-0.949$ ), indicating that high-quality gene expression data had been obtained from all placental samples for meaningful comparative analyses. Across all placental mRNA profiles, the top 16 expressed gene transcripts were $C S H 1, C S H 2, C G A, C G B$, HBA1, HBA2, PSG1, PSG2, PSG3, HBG2, GH2, and CSHL1, specifically associated with pregnancy, and KISS1, H19, TFPI2, and FBLN1, mainly known to be associated with oncogenesis and tumor suppression (Table 2). All these genes have been previously shown to be highly expressed in independent placental samples analyzed by both microarray (Sood et al., 2005) and RNA-seq (Kim et al., 2012) methodologies. In all cases, none of these genes were differentially expressed in the growth-discordant placenta pairs.

To identify differentially expressed genes in the smaller of the two growth-discordant placentas, the fold change for each transcript was plotted against its relative abundance (Figure 2, selected plots). The subset of the statistically significant transcripts $(p<.05)$ with a fold change of $>2$ were compared across all growth-discordant placenta pairs. Two genes, leptin $(L E P)$ and age-related maculopathy susceptibility 2 (ARMS2), were found to be specifically up-regulated to different degrees in all eight growth-discordant placentas (Table 2). Importantly, the expression levels of these two genes were relatively similar between the smaller and larger placentas of the three growth-concordant twins, suggesting that up-regulation of both $L E P$ and ARMS2 mRNA was associated with growth discordance.

Independent confirmation of LEP and ARMS2 mRNA differential expression was performed by qPCR on a second placental biopsy taken in close proximity to the first biopsy used for RNA-seq. Up-regulation of LEP and ARMS2 mRNA was also exclusively observed in each of the smaller of the two growth-discordant placentas at levels, generally similar to those measured by RNA-seq (Figure 3). Levels of increased LEP mRNA expression in the smaller placenta varied from as low as 7.2-fold (sample 228) to as high as 1,774-fold (sample 170). In contrast, levels of increased ARMS2 mRNA expression in the smaller placenta were generally lower, ranging from 3.5-fold (sample 228) to 53.4-fold (sample 170).

Given that the three control growth-concordant placenta pairs used in the RNA-seq and PCR studies were of a slightly higher gestational age compared to the growthdiscordant pairs (Table 1), we further analyzed LEP and ARMS2 mRNA expression levels by qPCR in three additional growth-concordant placentas $(397,424$, and 480) with similar gestational ages to the eight growth-discordant MCDA twin placentas (Table 1). In all three cases, we confirmed that the levels of LEP and ARMS2 mRNA were similar between the smaller and larger placentas in these independent control samples (Figure 3).

To further determine whether leptin and ARMS2 were also differentially expressed at the protein level, immunohistochemistry (IHC) was conducted on paraffin embedded tissue sections from selected growth-discordant placental samples (Figure 4). Strong leptin staining was consistently observed in approximately $5-10 \%$ of blood vessels and the surrounding chorionic villous cells of the smaller placenta. In contrast, all the blood vessels cells in the larger placenta showed relatively weak or no leptin staining. ARMS2 staining was observed in all placental cell types in both twin placentas, although marginally increased staining was also 


\section{TABLE 2}

List of Highly and Differentially Expressed Placental Genes

\begin{tabular}{|c|c|c|c|}
\hline Locus & Gene & RPKM value ${ }^{a}$ & Gene name \\
\hline \multicolumn{4}{|c|}{ A. Highly expressed genes in both growth-discordant and concordant MCDA twin placentas } \\
\hline Chr17:61972267-61974021 & $\mathrm{CSH} 1$ & 205841.7 & Chorionic somatomammotropin hormone 1 (placental lactogen) \\
\hline Chr17:61949371-61951089 & $\mathrm{CSH} 2$ & 130560.8 & Chorionic somatomammotropin hormone 2 \\
\hline Chr6:87795215-87804865 & CGA & 20432.75 & Glycoprotein hormones, alpha polypeptide \\
\hline Chr1:204159468-204165619 & KISS1 & 14540.28 & KiSS-1 metastasis-suppressor \\
\hline Chr7:93885397-93890991 & TFPI2 & 6019.564 & Tissue factor pathway inhibitor 2 \\
\hline Chr22:45898718-45997014 & FBLN1 & 4182.648 & Fibulin 1 \\
\hline Chr19:49526125-49527632 & $C G B$ & 3931.729 & Chorionic gonadotropin, beta polypeptide \\
\hline Chr19:43370612-43383871 & PSG1 & 3716.856 & Pregnancy specific beta-1-glycoprotein 1 \\
\hline Chr16:222845-223709 & HBA2 & 3690.052 & Hemoglobin, alpha 2 \\
\hline Chr11:2016405-2019065 & H19 & 3627.351 & $\mathrm{H} 19$, imprinted maternally expressed transcript (non-coding region) \\
\hline Chr19:43064210-43082741 & PSG2 & 3378.741 & Pregnancy specific beta-1-glycoprotein 2 \\
\hline Chr19:42721642-42740516 & PSG3 & 3186.883 & Pregnancy specific beta-1-glycoprotein 3 \\
\hline Chr16:226678-227520 & HBA1 & 3132.802 & Hemoglobin, alpha 1 \\
\hline Chr17:63909605-63911258 & CSHL1 & 2713.01 & Chorionic somatomammotropin hormone-like 1 \\
\hline Chr11:5274420-5276011 & HBG2 & 2679.881 & Hemoglobin, gamma G \\
\hline Chr17:63880212-63881942 & GH2 & 2433.652 & Growth hormone 2 \\
\hline Locus & Gene & Expression trend & Gene name \\
\hline \multicolumn{4}{|c|}{ B. Differentially expressed genes in the smaller of the growth-discordant MCDA twin placentas } \\
\hline $\begin{array}{l}\text { chr7:127881330-127897682 } \\
\text { chr10:124214178-124216868 }\end{array}$ & $\begin{array}{l}\text { LEP } \\
\text { ARMS2 }\end{array}$ & $\begin{array}{l}\text { Higher } \\
\text { Higher }\end{array}$ & $\begin{array}{l}\text { Leptin } \\
\text { Age-related maculopathy susceptibility } 2\end{array}$ \\
\hline
\end{tabular}

Note: Note: ${ }^{\text {a }}$ PKM values represent the relative transcript abundance.

consistently observed in the microvillous membranes of the smaller placenta.

\section{Discussion}

In this pilot study of clinically defined growth-discordant and concordant MCDA placentas (Table 1), we successfully applied next generation RNA-seq to elucidate differentially expressed placental genes involved in growth discordance. This was performed using human models of growthdiscordant MCDA twin pregnancies in order to reduce the contribution of maternal factors and focus specifically on identifying novel placental factors. Detailed comparison of the poly $\mathrm{A}^{+}$transcriptomes derived from eight growthdiscordant twin MCDA placentas identified two genes, LEP and ARMS2. The RNA-seq results were independently confirmed at the mRNA and protein level by qPCR and IHC analyses.

From the very large number of genes found to be expressed in placental tissue, remarkably, only ARMS2 and $L E P$ were significantly up-regulated in all of the smaller discordant MCDA twin placentas, leading us to speculate on their possible functional roles. The first gene that was found to be significantly up-regulated in the growth restricted twin placenta was $L E P$. In a previous study that examined placental angiogenic gene expression in MCDA growthdiscordant twin placentas, three genes LEP, Flt (fms-like tyrosine kinase), and Eng (Endoglin) were consistently upregulated in the smaller of the co-twin placentas, although leptin showed the strongest association (Schrey et al., 2013) and agrees with the findings in this study. Further, in other independent studies, higher placental levels of leptin gene expression has also been documented in cases of pre-eclampsia and insulin-dependent gestational diabetes, as well as in singleton pregnancies with small gestational age placentas and placentas with IUGR (Sagawa et al., 2002). Leptin is known to be expressed in a variety of tissues; in particular, the white and brown adipose tissue of the placenta (Allison \& Myers, 2014). The most recognized function of leptin is regulation of the amount of stored fat in the body and thus is well-known as the 'satiety' hormone (Allison \& Myers, 2014; Maffei et al., 1995).

Despite its important homeostatic role in regulating hunger, leptin has also been shown to have important autocrine effects on placental growth and function (PérezPérez et al., 2015). Of further interest are two previous reports of leptin acting as a pro-angiogenic factor in the cornea of the eye (Sierra-Honigmann et al., 1998) and in developing embryos (Talavera-Adame et al., 2008). In this study, IHC analyses revealed that $10-20 \%$ of the blood vessels as well as the immediate surrounding chorionic villous cells had increased leptin expression, exclusively in the smaller placenta. This observation would support the notion that leptin may act as one of the key angiogenic factors to increase vascularization in specific regions of the placenta when under metabolic stress. Therefore, increased local levels of leptin expression, in concert with other angiogenic factors such as VEGF (Schrey et al., 2013), may be involved in modifying the vascular endothelium of the growth-restricted placenta. Thus, we postulate that during growth restriction, leptin signaling may form part of a critical survival or compensatory mechanism to increase blood supply and nutrient flow.

The second gene found to be up-regulated in growth restricted placenta was the ARMS2 gene associated with 
152-L vs. $152-S$

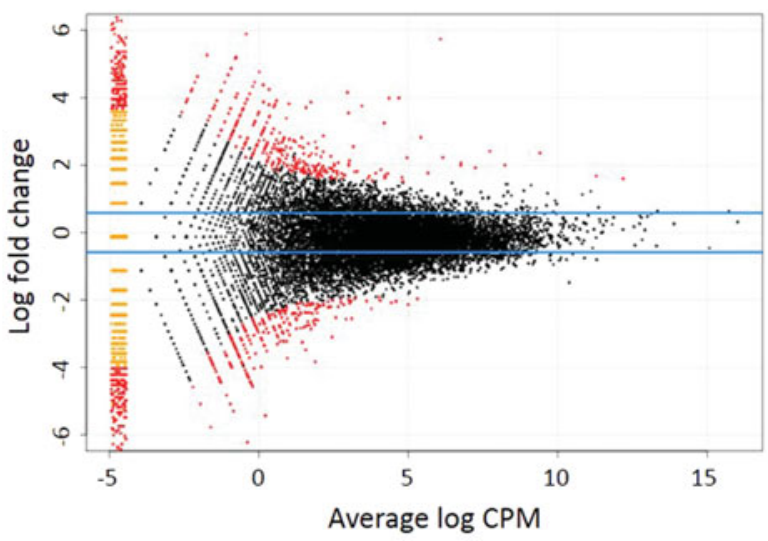

144-L vs. $144-S$

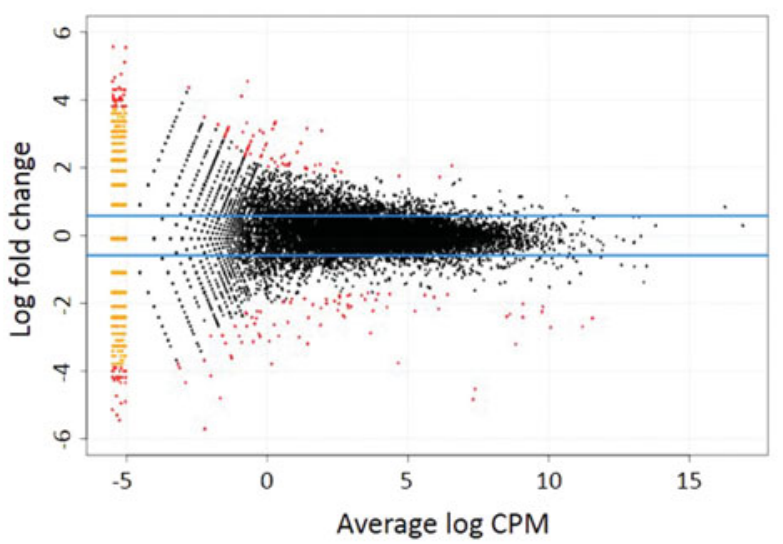

197-L vs. 197-S

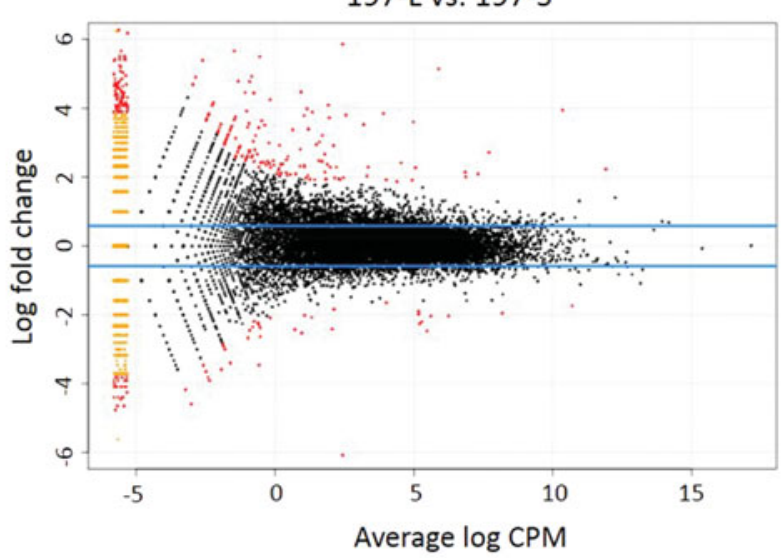

202-L vs. 202-S

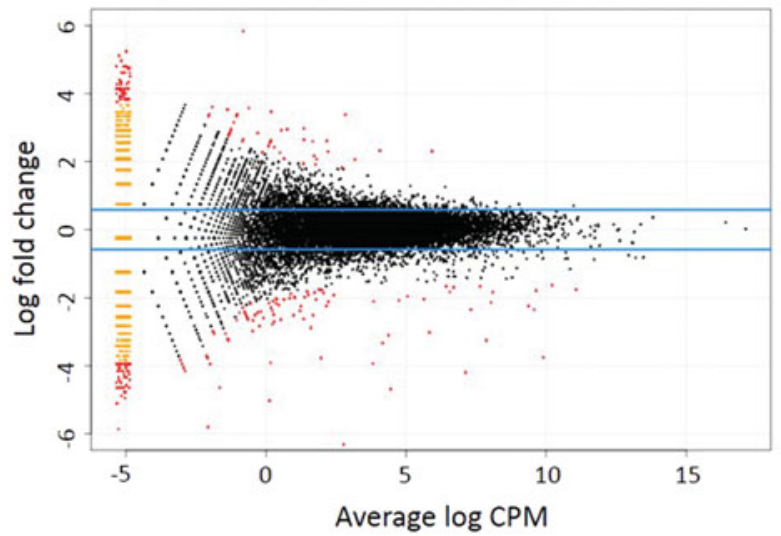

FIGURE 2.

(Colour online) Changes in mRNA gene expression between growth-discordant MCDA twin placentas. Note: Transcript distributions are plotted as log fold change (differential expression) versus average log CPM (abundance). The upper blue line marks 2-fold up-regulation and the lower blue line marks 2-fold down-regulation. The distribution of transcript expression change is shown by the cloud of black dots (non-significant change, $p>.05$ ) and red dots (significant change, $p<.05$ ). Representative plots for four of the eight growth-discordant MCDA placentas $(152,197,144$, and 202) are shown.

age-related maculopathy, which is a degenerative condition of the retina that leads to progressive visual loss (HorieInoue \& Inoue, 2014; Ratnapriya \& Chew, 2013). To date, the function of ARMS2 has remained elusive due to a lack of a non-human homologue for manipulation in an animal model. ARMS2 mRNA is known to be highly expressed in the both the retina (Wang et al., 2011) and in the placenta (Fritsche et al., 2008), and the mature form of the protein is secreted into the cytosol (Kortvely et al., 2010). In the retina, ARMS2 binds to a number of extracellular matrix proteins implicated in macular dystrophies (Kortvely et al., 2010). Further, it is localized mainly to regions of choroid pillars in the retina where pathological drusen deposits occur in patients with age-related maculopathy (Ratnapriya \& Chew, 2013). Thus, based on the available evidence by association with age-related maculopathy, we speculate that elevated levels of ARMS2 protein detected in the growth- restricted twin placenta may reflect an underlying pathology originating from dysfunction of the normal extracellular matrix. Furthermore, as ARMS2 mRNA is almost exclusively expressed in the placenta (Fritsche et al., 2008) and is secreted (Kortvely et al., 2010), it may represent a useful measurable biomarker of growth discordance in MCDA twins.

One limitation of the study was that the growthdiscordant MCDA placentas consented for comparative analyses were obtained after deliveries during the late third trimester of pregnancy; thus, we were only able to focus on genes exerting an effect at the end stage of growth discordance. Obtaining access to placental mRNA, prospectively during the course of a MCDA twin pregnancy would allow the identification of placental genes more relevant to the initiation and perpetuation of growth discordance. One emerging approach is the analysis of the circulating RNA 
A. Leptin

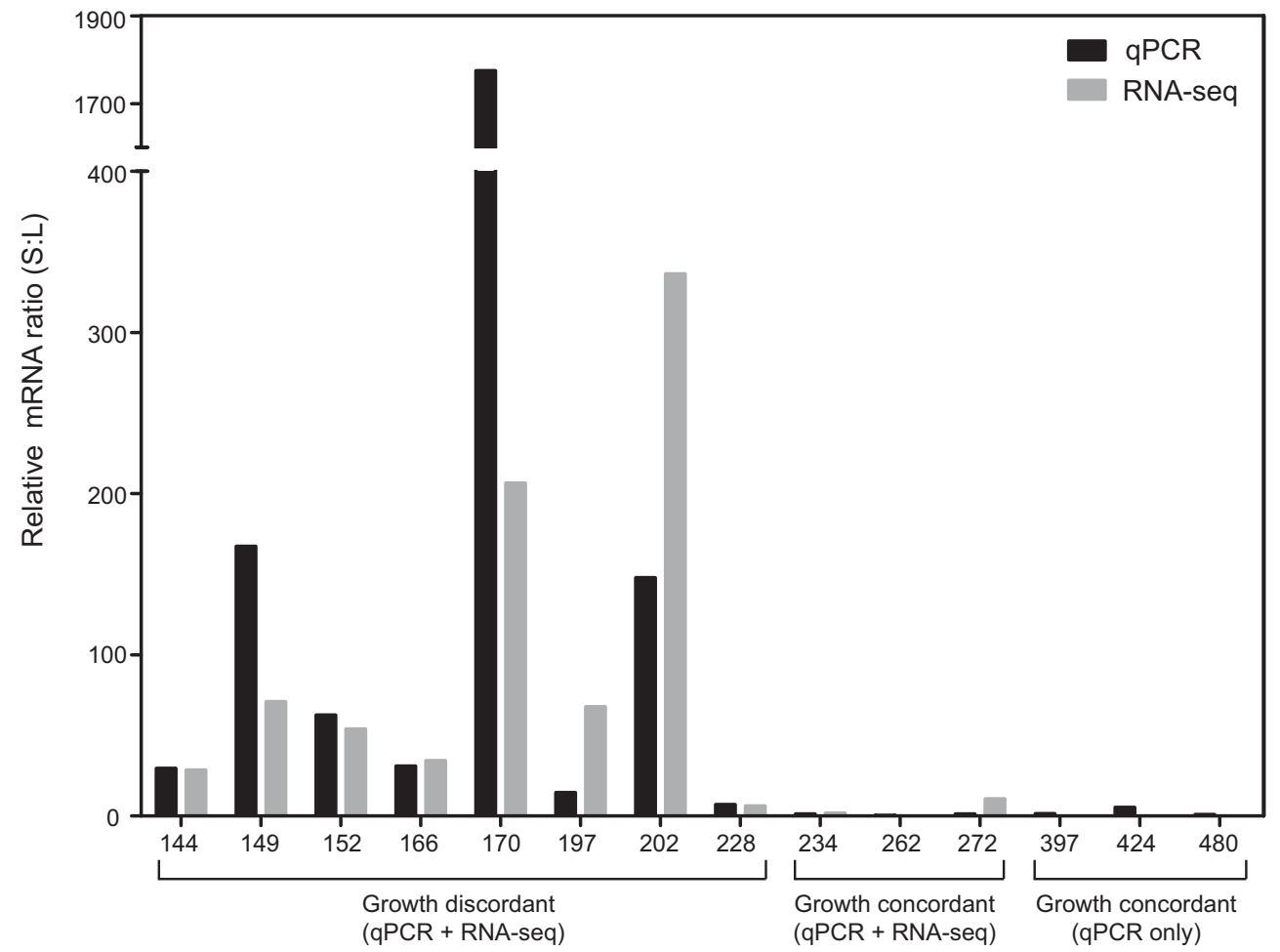

B. ARMS2

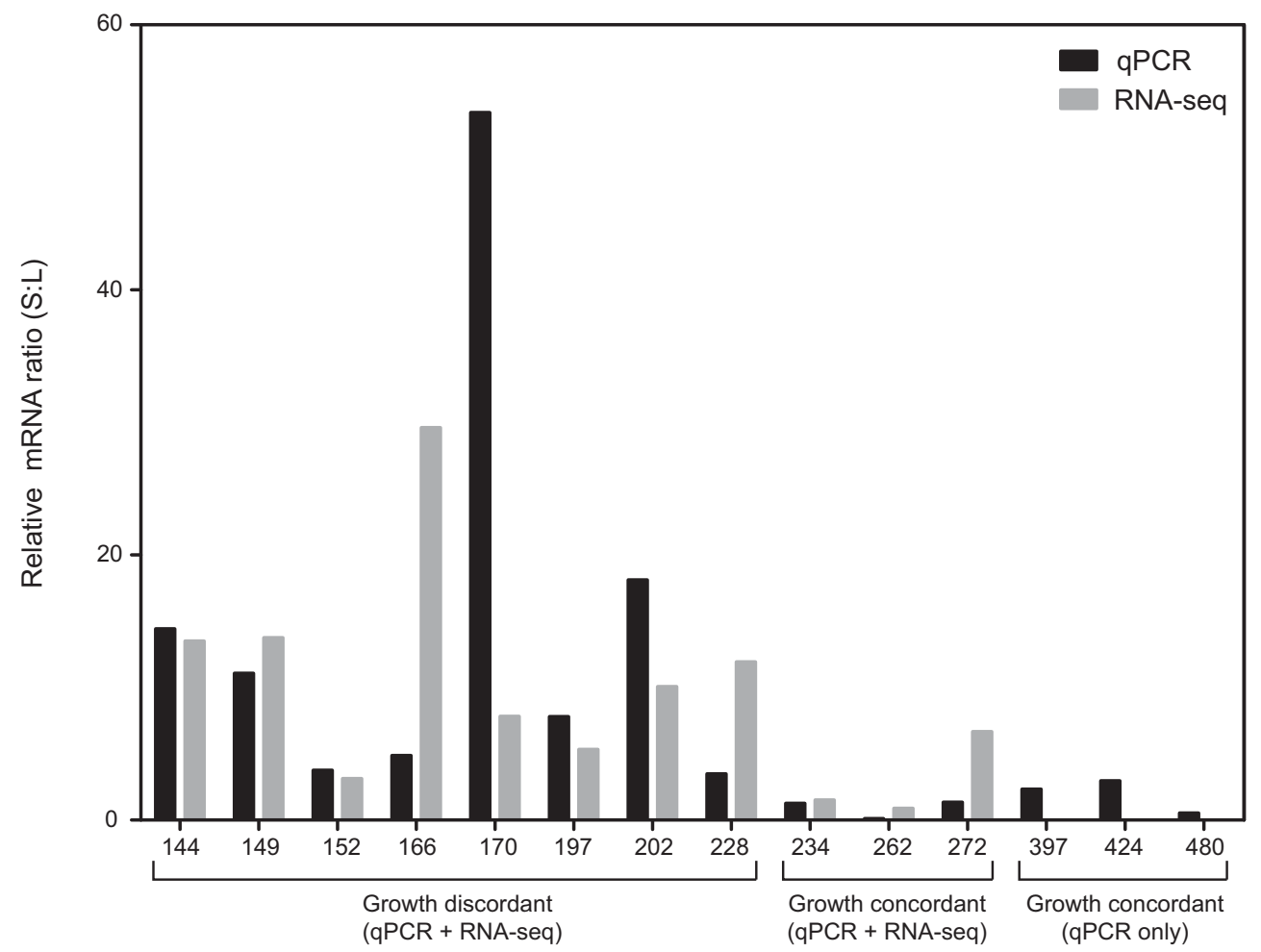

FIGURE 3.

Differential expression of LEP and ARMS2 mRNA. Note: The relative expression levels of LEP mRNA (A) and ARMS2 mRNA (B) were determined by the ratio of transcript abundance between the small (S) and large (L) placenta of the growth-discordant and concordant MCDA placentas. qPCR and RNA sequencing results are shown by black and grey bars, respectively. 
Leptin IHC
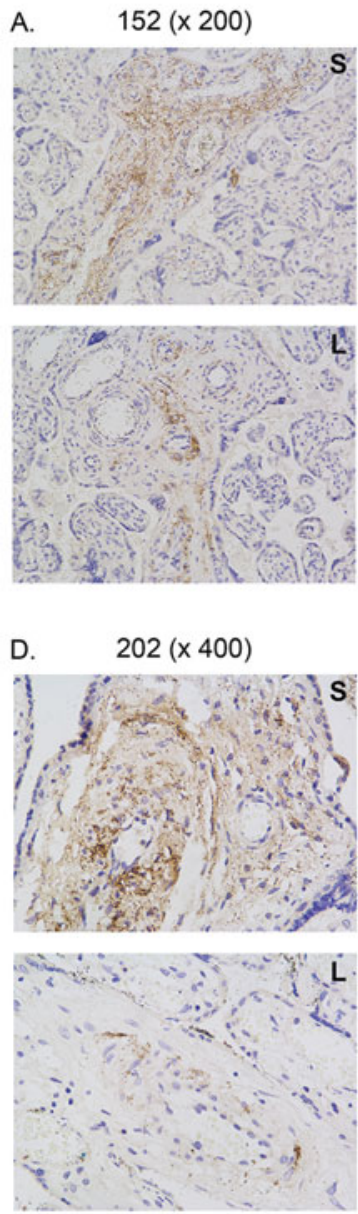

\section{ARMS2 IHC}

G.

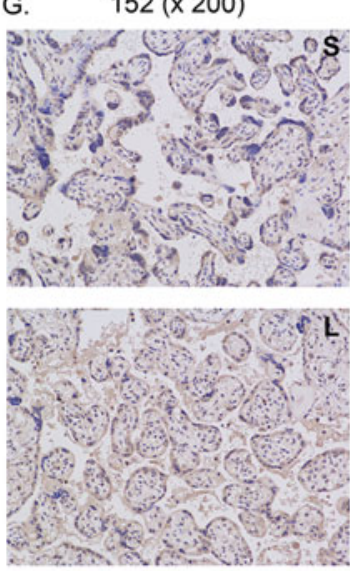

B.
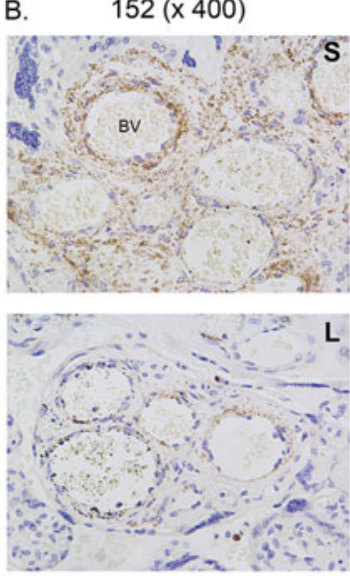

E. $202(x 400)$
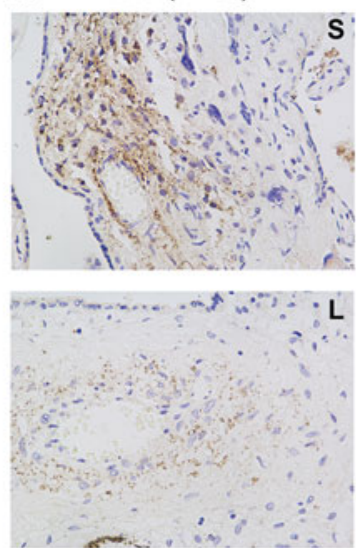

H.
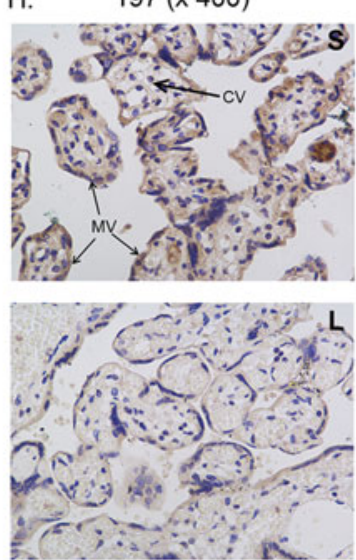
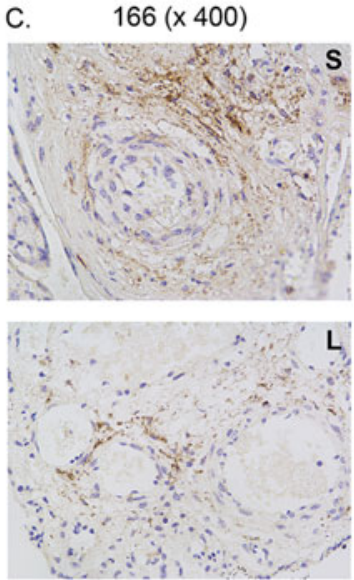

F. $\quad 166 \mathrm{NC}(\times 200)$
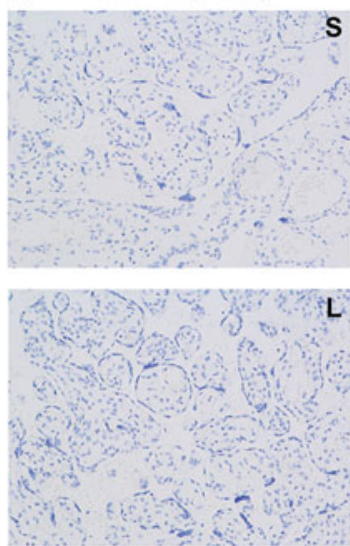

I. $166 \mathrm{NC}(\mathrm{x} 400)$
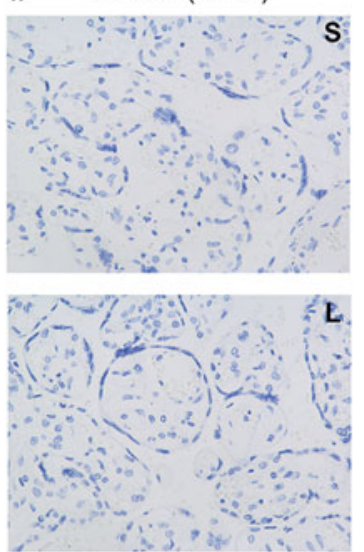

\section{FIGURE 4.}

(Colour online) Differential leptin and ARMS2 protein expression. Note: IHC using leptin and ARMS2 specific antibodies was performed on selected tissue sections of growth-discordant placentas (magnification either $\times 200$ or $\times 400$ ). IHC results for smaller (S) and larger (L) placenta are shown in the top and bottom panels, respectively. H\&E blue staining indicates cellular nuclei and brown cellular staining represents positive leptin (panels $A, B, C, D$, and E) and ARMS2 (panels $G$ and H) staining. There was no staining of the negative control sections (panels $\mathrm{F}$ and I). $\mathrm{BV}=$ blood vessel (panel $\mathrm{B}$ ), $\mathrm{CV}=$ chorionic villous, and $\mathrm{MV}=$ microvillous (panel $\mathrm{H}$ ). 
fraction in the maternal plasma during pregnancy (Koh et al., 2014). Robust techniques for isolating the total RNA fraction (Spornraft et al., 2014) and identifying key elements of the entire transcriptome, including mRNA and miRNA (Huang et al., 2013), are already well-advanced. In addition, proof of concept for detection of placental-specific mRNAs such as H19 that was found to be highly expressed in our study, as well as pregnancy-specific RNAs, has now been recently demonstrated (Tsui et al., 2014). Therefore, multiple blood sampling to obtain a liquid plasma RNA biopsy would be an ethically acceptable research study for women with MCDA twin pregnancies. This type of minimally non-invasive approach may provide novel insights into the key genes and biological pathways involved in the development of growth discordance in MCDA twins. Furthermore, such an approach would also have potential to reveal valuable measurable biomarkers for identifying and monitoring MCDA twin pregnancies that are at high risk for growth discordance.

In conclusion, we identified two placental proteins, leptin and ARMS2, strongly associated with growth discordance in MCDA twins. We postulate that leptin and ARMS2 may play a key role to drive angiogenesis as a survival mechanism to compensate for the decreased blood and nutrient supply in the growth-restricted MCDA twin. Further, since both leptin and ARMS2 are produced as soluble proteins, they may also have potential as secreted biomarkers for predicting growth discordance in MCDA twins. Continued studies are required to understand the key epigenetic changes in growth-discordant MCDA twin pregnancies, so that medical interventions or potential therapies can be developed to alleviate the adverse perinatal outcomes associated with this pregnancy complication.

\section{Acknowledgments}

We thank the staff in the Fetal Medicine Unit and Prenatal Diagnosis Center, Department of Obstetrics in Shanghai First Maternity and Infant Hospital for their clinical support during the course of this research project. This work was supported by the Fund of Shanghai Municipal Science and Technology Commission to Dr Luming Sun (grant number 16411963100).

\section{Conflict of Interest}

LS, JZ, and DSC are employees of Berry Genomics Corporation, Beijing.

\section{References}

Acosta-Rojas, R., Becker, J., Munoz-Abellana, B., Ruiz, C., Carreras, E., Gratacos, E., \& Catalunya and Balears Monochorionic Network. (2007). Twin chorionicity and the risk of adverse perinatal outcome. International Journal of $G y$ naecology and Obstetrics, 96, 98-102.
Allison, M. B., \& Myers, M. G. Jr. (2014). 20 years of leptin: Connecting leptin signaling to biological function. Journal of Endocrinology, 223, T25-T35.

Bejar, R., Vigliocco, G., Gramajo, H., Solana, C., Benirschke, K., \& Resnik, R. (1990). Antenatal origin of neurologic damage in newborn infants. II. Multiple gestations. American Journal of Obstetrics and Gynecology, 162, 1230-1236.

Bell, J. T., \& Saffery, R. (2012). The value of twins in epigenetic epidemiology. International Journal of Epidemiology, $41,140-150$.

Chang, Y. L., Chang, S. D., Chao, A. S., Hsieh, P. C., Wang, C. N., \& Wang, T. H. (2009). Clinical outcome and placental territory ratio of monochorionic twin pregnancies and selective intrauterine growth restriction with different types of umbilical artery doppler. Prenatal Diagnosis, 29, 253256.

Cosmi, E., Visentin, S., Favretto, D., Tucci, M., Ragazzi, E., Viel, G., \& Ferrara, S. D. (2013). Selective intrauterine growth restriction in monochorionic twin pregnancies: Markers of endothelial damage and metabolomic profile. Twin Research and Human Genetics, 16, 816-826.

Fritsche, L. G., Loenhardt, T., Janssen, A., Fisher, S. A., Rivera, A., Keilhauer, C. N., \& Weber, B. H. (2008). Agerelated macular degeneration is associated with an unstable ARMS2 (LOC387715) mRNA. Nature Genetics, 40, 892896.

Gao, Y., He, Z., Wang, Z., Luo, Y., Sun, H., Zhou, Y., ... Jiang, S. (2012). Increased expression and altered methylation of HERVWE1 in the human placentas of smaller fetuses from monozygotic, dichorionic, discordant twins. PLoS One, 7, e33503.

Gordon, L., Joo, J. H., Andronikos, R., Ollikainen, M., Wallace, E. M., Umstad, M. P., ... Craig, J. M. (2011). Expression discordance of monozygotic twins at birth: Effect of intrauterine environment and a possible mechanism for fetal programming. Epigenetics, 6, 579-592.

Gratacós, E., Lewi, L., Muñoz, B., Acosta-Rojas, R., Hernandez-Andrade, E., Martinez, J. M., ... Deprest, J. (2007). A classification system for intrauterine growth restriction in monochorionic pregnancies according to umbilical artery doppler flow in the smaller twin. Ultrasound in Obstetrics \& Gynecology, 30, 28-34.

Hack, K. E., Nikkels, P. G., Koopman-Esseboom, C., Derks, J. B., Elias, S. G., van, Gemert, M. J., \& Visser, G. H. (2008). Placental characteristics of monochorionic diamniotic twin pregnancies in relation to perinatal outcome. Placenta, 29, 976-981.

Horie-Inoue, K., \& Inoue, S. (2014). Genomic aspects of agerelated macular degeneration. Biochemical and Biophysical Research Communications, 452, 263-275.

Huang, X., Yuan, T., Tschannen, M., Sun, Z., Jacob, H., Du, M., ... Wang, L. (2013). Characterization of human plasmaderived exosomal RNAs by deep sequencing. BMC Genomics, 14, 319.

Kaminsky, Z. A., Tang, T., Wang, S. C., Ptak, C., Oh, G. H., Wong, A. H., ... Petronis, A. (2009). DNA methylation profiles in monozygotic and dizygotic twins. Nature Genetics, $41,240-245$. 
Kim, D., Pertea, G., Trapnell, C., Pimentel, H., Kelley, R., \& Salzberg, S. L. (2013). TopHat2: Accurate alignment of transcriptomes in the presence of insertions, deletions and gene fusions. Genome Biology, 14, R36.

Kim, J., Zhao, K., Jiang, P., Lu, Z. X., Wang, J., Murray, J. C., \& Xing, Y. (2012). Transcriptome landscape of the human placenta. BMC Genomics, 13, 115.

Koh, W., Pan, W., Gawad, C., Fan, H. C., Kerchner, G. A., Wyss-Coray, T., ... Quake, S. R. (2014). Noninvasive in vivo monitoring of tissue-specific global gene expression in humans. Proceedings of the National Academy of Sciences of the United States of America, 111, 7361-7366.

Kortvely, E., Hauck, S. M., Duetsch, G., Gloeckner, C. J., Kremmer, E., Alge-Priglinger, C. S., ... Ueffing, M. (2010). ARMS2 is a constituent of the extracellular matrix providing a link between familial and sporadic age-related macular degenerations. Investigative Ophthalmology \& Visual Science, 51, 79-88.

Lewi, L., Cannie, M., Blickstein, I., Jani, J., Huber, A., Hecher, K., ... Deprest, J. (2007). Placental sharing, birthweight discordance, and vascular anastomoses in monochorionic diamniotic twin placentas. American Journal of Obstetrics and Gynecology, 197, 587e1-587e8.

Lewi, L., Devlieger, R., De Catte, L., \& Deprest, J. (2014). Growth discordance. Best Practice Research Clinical Obstetrics \& Gynaecology, 28, 295-303.

Li, M. C., Fang, Q., He, Z. M., Gao, Y., \& Zhou, Y. (2013). Placental expression of osteopontin(OPN) in monochorionic twins with discordant growth. Placenta, 34, 288290.

Liang, D., Lv, W., Wang, H., Xu, L., Liu, J., Li, H., ... Wu, L. (2013). Non-invasive prenatal testing of fetal whole chromosome aneuploidy by massively parallel sequencing. Prenatal Diagnosis, 33, 409-415.

Maffei, M., Halaas, J., Ravussin, E., Pratley, R. E., Lee, G. H., Zhang, Y., ... Ranganathan, S. (1995). Leptin levels in human and rodent: Measurement of plasma leptin and ob RNA in obese and weight-reduced subjects. Nature Medicine, 1, 1155-1161.

Marr, A. K., Boughorbel, S., Presnell, S., Quinn, C., Chaussabel, D., \& Kino, T. (2016). A curated transcriptome dataset collection to investigate the development and differentiation of the human placenta and its associated pathologies. F1000Research, 5, 305.

McCarthy, C., Cotter, F. E., McElwaine, S., Twomey, A., Mooney, E. E., Ryan, F., \& Vaughan, J. (2007). Altered gene expression patterns in intrauterine growth restriction: Potential role of hypoxia. American Journal of Obstetrics and Gynecology, 196, 70.e1-70.e6.

Mortazavi, A., Williams, B. A., McCue, K., Schaeffer, L., \& Wold, B. (2008). Mapping and quantifying mammalian transcriptomes by RNA-Seq. Nature Methods, 5, 621628.

Nishizawa, H., Ota, S., Suzuki, M., Kato, T., Sekiya, T., Kurahashi, H., \& Udagawa, Y. (2011). Comparative gene expression profiling of placentas from patients with severe pre-eclampsia and unexplained fetal growth restriction. $R e$ productive Biology and Endocrinology, 9, 107.
Pérez-Pérez, A., Sánchez-Jiménez, F., Maymó, J., Dueñas, J. L., Varone, C., \& Sánchez-Margalet, V. (2015). Role of leptin in female reproduction. Clinical Chemistry and Laboratory Medicine, 53, 15-28.

Ratnapriya, R., \& Chew, E. Y. (2013). Age-related macular degeneration - clinical review and genetics update. Clinical Genetics, 84, 160-166.

Robinson, M. D., McCarthy, D. J., \& Smyth, G. K. (2010). EdgeR: A bioconductor package for differential expression analysis of digital gene expression data. Bioinformatics, 26, 139-140.

Sagawa, N., Yura, S., Itoh, H., Mise, H., Kakui, K., Korita, D., ... Fujii, S. (2002). Role of leptin in pregnancy - a review. Placenta, 23(Suppl. A), S20-S26.

Schrey, S., Kingdom, J., Baczyk, D., Fitzgerald, B., Keating, S., Ryan, G., \& Drewlo, S. (2013). Leptin is differentially expressed and epigenetically regulated across monochorionic twin placenta with discordant fetal growth. Molecular $\mathrm{Hu}$ man Reproduction, 19, 764-772.

Sierra-Honigmann, M. R., Nath, A. K., Murakami, C., GarcíaCardeña, G., Papapetropoulos, A., Sessa, W. C., ... FloresRiveros, J. R. (1998). Biological action of leptin as an angiogenic factor. Science, 281, 1683-1686.

Simonazzi, G., Curti, A., Cattani, L., Rizzo, N., \& Pilu, G. (2013). Outcome of severe placental insufficiency with abnormal umbilical artery doppler prior to fetal viability. BJOG-an International Journal of Obstetrics and Gynaecology, 120, 754-757.

Sitras, V., Paulssen, R., Leirvik, J., Vartun, A., \& Acharya, G. (2009). Placental gene expression profile in intrauterine growth restriction due to placental insufficiency. Reproductive Sciences, 16, 701-711.

Sood, R., Zehnder, J. L., Druzin, M. L., \& Brown, P. O. (2005). Gene expression patterns in the human placenta. Proceedings of the National Academy of Sciences of the United States of America, 103, 5478-5483.

Spornraft, M., Kirchner, B., Haase, B., Benes, V., Pfaffl, M. W., \& Riedmaier, I. (2014). Optimization of extraction of circulating RNAs from plasma - enabling small RNA sequencing. PLoS One, 9, e107259.

Talavera-Adame, D., Xiong, Y., Zhao, T., Arias, A. E., SierraHonigmann, M. R., \& Farkas, D. L. (2008). Quantitative and morphometric evaluation of the angiogenic effects of leptin. Journal of Biomedical Optics, 13, 064017.

Tsui, N. B., Jiang, P., Wong, Y. F., Leung, T. Y., Chan, K. C., Chiu, R. W., ... Lo, Y. M. (2014). Maternal plasma RNA sequencing for genome-wide transcriptomic profiling and identification of pregnancy-associated transcripts. Clinical Chemistry, 60, 954-962.

Valsky, D. V., Eixarch, E., Martinez, J. M., Crispi, F., \& Gratacos, E. (2010). Selective intrauterine growth restriction in monochorionic twins: Pathophysiology, diagnostic approach and management dilemmas. Seminars in Fetal \& Neonatal Medicine, 15, 342-348.

Valsky, D. V., Eixarch, E., Martinez, J. M., \& Gratacós, E. (2010). Selective intrauterine growth restriction in diamniotic twin pregnancies. Prenatal Diagnosis, 30, 719726. 
Wang, G., Scott, W. K., Whitehead, P., Court, B. L., Kovach, J. L., Schwartz, S. G., ... Pericak-Vance, M. A. (2011). A novel ARMS2 splice variant is identified in human retina. Experimental Eye Research, 94, 187-191.
Yu, C. C., Furukawa, M., Kobayashi, K., Shikishima, C., Cha, P. C., Sese, J., ... Toda, T. (2012). Genome-wide DNA methylation and gene expression analyses of monozygotic twins discordant for intelligence levels. PLoS One, 7, e47081. 